\title{
Emerging models for cross-border online licensing
}

Schwemer, Sebastian Felix

Published in:

User-Generated Law

Publication date:

2016

Document version

Other version

Citation for published version (APA):

Schwemer, S. F. (2016). Emerging models for cross-border online licensing. In T. Riis (Ed.), User-Generated Law: Re-Constructing Intellectual Property Law in a Knowledge Society (pp. 77-98). Edward Elgar Publishing. 


\title{
Emerging models for cross-border online licensing
}

\author{
Sebastian Schwemer* \\ Center for Informations- og innovationsret (CIIR), \\ Københavns Universitet
}

Draft version: 1 May 2015

- Forthcoming as Chapter 4 in Thomas Riis (ed), User Generated Law,

Edward Elgar (2015) -

\section{Introduction}

Since the early 2000s when players outside the traditional music ecosystem started to commercialise new forms of digital distribution, the consumption of creative content has rapidly shifted over to Internet-based services. In response to consumers' craving for modern and more convenient forms of consuming entertainment - all enabled by faster Internet connections - digital service providers like Spotify, YouTube or Soundcloud have made interactive on-demand streaming the main form of music consumption via the Internet ${ }^{1}$ In Denmark, a recent assessment showed that streaming accounted for as much as $58.5 \%$ of all revenues from recorded music, and in Norway the figure was 77 $\% 2$

Concurrently, the traditional picture of national exploitation of copyright has changed. The licensing of novel uses of copyright-protected materials from rightholders and their organisations has been described anything but smooth. It appears that traditional licensing mechanisms and arrangements have not always been able to facilitate right-clearance in the changed environment. In the previous chapter, various aspects of the collective management of copyright were examined, including the traditional rationale of reducing transaction costs

\footnotetext{
*sebastian.felix.schwemer@jur.ku.dk.

${ }^{1}$ YouTube was founded in 2005; Spotify dates back to 2006; Deezer, Grooveshark and Soundcloud launched in 2007. In 2012, the European Commission counted more than 300 music streaming services available in the EU.

${ }^{2}$ The numbers refer to 2014 (Denmark) and the first half of 2014 (Norway) respectively. http://www.ifpi.dk/?q=content/fortsat-v\%C3\%A6kst-i-dansk-musik http://www . ifpi.no/flewnyheter/item/67-halvarsstatistikk-2014
} 
of collective management organisations $(\mathrm{CMOs}) \mathrm{H}^{3}$ In the digital world, some of these economic rationales for collective administration have been questioned 4

New licensing arrangement and entities have emerged: sometimes influenced or accompanied by regulatory action and sometimes not. In the EU, restrictions that prevent multi-territorial licensing (which means the licensing of music that covers more than one jurisdictional territory at a time) are a focal point for policymakers and scholars 5 The European legislator has been observing the area for at least twenty years ${ }^{6}$ In this period, various institutional actors (such as different Directorate Generals within the European Commission) have taken action. Recently, the facilitation of licenses even spearheaded the EU Commission's Digital Agenda as 'Action 1' where the cross-border licensing dimension attracted the legislator's special attention and culminated in the adoption of Directive 2014/26/EU on collective management of copyright and related rights and multi-territorial licensing of rights in musical works for online use in the internal market (hereinafter "CRM Directive") 7

According to the user generated law framework, "law that accommodates the needs of the knowledge society" is characterized by (1) flexible norms (2) with cross-border scope and (3) which are industry- and subject-specific. This chapter revisits the developments in the field with regards to licensing arrangements and tests whether the user generated law methodology can construe the emerging legal regulatory (based on contracts and laws) and non-regulatory models (based on technology and social norms). The history of these cross-border licensing models can to a large extent be seen as interplay between regulatory

\footnotetext{
${ }^{3}$ A collecting society (now commonly referred to as a 'collective management organisation' within the EU) is defined in Article 3 lit (a) Directive 2014/26/EU as an organisation which "is authorised by law or by way of assignment, license or any other contractual arrangement to manage copyright or rights related to copyright on behalf of more than one rightholder, for the collective benefit of those rightholders, as its sole or main purpose, and which fulfils one or both of the following criteria: (i) it is owned or controlled by its members; (ii) it is organised on a not-for-profit basis." Given the different shades between the national CMOs, the Directive does not refer to the level of solidarity or regulation as characteristics.

${ }^{4}$ See e.g. Josef Drexl, 'Competition in the field of collective management: preferring "creative competition" to allocative efficiency in European copyright law' in Paul Torremans (ed), Copyright Law, Handbook of Contemporary Research (Edward Elgar 2007), 261 or Ariel Katz, 'The Potential Demise of Another Natural Monopoly: New Technologies and the Administration of Performance Rights' (2006) 2(2) Journal of Competition Law and Economics.

${ }^{5}$ Lucie Guilbault,'The Draft Collective Management Directive' in Irini Stamatoudi and Paul Torremans (eds), EU Copyright Law, A commentary (Edward Elgar 2014), 698. e.g. notes that a significant portion of royalties derives from non-domestic repertoire, which makes the facilitation of multi-territorial licenses an important issue. The increasing demand for cross-border access and licensing solutions for different content types has also been one topic of the EU Commission's Copyright Consultation in 2014.

${ }^{6}$ See e.g. European Commission, Green Paper, Copyright and Related Rights in the Information Society (19.07.1995), COM(95), 382 final, 71.

${ }^{7}$ Directive $2014 / 26 /$ EU consists of two major parts: the first part establishes a governance and transparency framework for all collective management organisations. The second part establishes a set of rules specifically for multi-territorial licensing of music for online use by author CMOs.
} 
activity and private mechanisms. This is also the area of interplay that this chapter will focus upon.

First, the chapter examines the emergence of cross-border licensing models for online use, revisiting the distinct phases of model contracts, multi-territorial mono-repertoire licensing entities, licensing hubs, and the most recent forms of licensing and related regulatory activities. In its second part, the chapter analyses how well these developments accord with the user generated law methodology. Does the example of online licensing pass all phases of the theoretical model? Why have the licensing arrangements been created in the first place? Do determinants from the methodological model have an influence on the emergence of the specific user generated law? The chapter concludes with some broader observations on the applicability of the user generated law model.

\section{Emerging licensing models - stocktaking and outlook}

\subsection{Model contracts as user generated law - competition concerns and soft law}

Traditionally, mass uses of copyright protected works have been confined to the territory of specific countries. Rightholders (i.e. authors, composers, publishers, performers, and record labels for secondary uses) assign the administration of their rights to the respective national collective management organisation $(\mathrm{CMO}) 8$ In order to offer licenses for a wider repertoire covering global (nondomestic) repertoire, CMOs have entered into a complex network of so-called reciprocal representation agreements (RRAs) with each other 9 Hereby, along with its own national repertoire, a CMO obtains the right to license the repertoire of the CMOs with which it has a bilateral arrangement. As such, the traditional arrangement has revolved around national monopoly one-stop-shops which have licensed the entire world music repertoire for use in their respective domestic territories 10

Back in the 1970s, the European Commission did not have concerns regarding CMOs' practices "of restricting their activities to delimitated administration

\footnotetext{
${ }^{8}$ See e.g. A. Capobianco, 'Licencing of Music Rights: Media Convergence, Technological Developments and EC Competition Law' (2004) E.I.P.R. 113, 114. Thomas Riis, 'Collecting societies, competition, and the Services Directive' (2011) 6 Journal of Intellectual Property Law \& Practice 482-493. Violaine Dahin, 'The future of legal online music services in the European Union: a review of the EU Commission's recent initiatives in cross-border copyright management' (2010) 32(5) E.I.P.R. 223 or Tilman Lüder, 'The First Experience with EU-wide Online Music Licensing' (2007) GRUR Int. 649-658.

${ }^{9}$ This remains the norm. See e.g. recital 40 Directive 2014/26/EU. Also: Dahin, 223 and Lucie Guilbault \& Stef van Gompel, 'Collective Management in the European Union' in Daniel Gervais (ed), Collective Management of Copyright and Related Rights (Kluwer Law International 2010) 135.

${ }^{10}$ Peter Gyertyánfy, 'Collective Management of Music Rights in Europe After the CISAC Decision' (2010) IIC, 60.
} 
territories and of concluding representation agreements ${ }^{211}$ to national one-stopshop. In the early 2000s, the CMOs' umbrella organisations developed two standard agreements which amended pre-existing agreements ${ }^{12}$ The model contracts aimed at enabling licensees to obtain a license for online exploitation of the worldwide repertoire from their national CMO. This time, however, soon after the two standard agreements were reached, the Directorate General Competition of the European Commission expressed competition concerns regarding a customer allocation clause contained in both agreements - despite its support for the underlying one-stop shop principle ${ }^{13}$ The agreements have not been renewed and concluded respectively. In proceedings related to the Online $\mathrm{Mu}-$ sic Recommendation (see below), stakeholders pointed towards the difficulty of reconciling the digital ubiquitous nature of the Internet with traditional RRAs which did not foresee that CMOs grant licenses beyond their home territory ${ }^{14}$

The CISAC proceedings dealt with model law and the systematic delineation of territory, too 15 In reviewing a process which dated back to a complaint in 2000, the Directorate Competition assessed RRAs between 24 European authorCMOs based on a CISAC model contract ${ }^{16}$ In its decision from 2008, the Commission took the standpoint that a series of aspects, including membership and territorial restrictions incorporated in the RRAs concluded between the CMOs, constituted infringements of competition rules, Article 101 TFEU ${ }^{17}$ The defendant CMOs were obliged to strictly bilaterally renegotiate their representation agreements ${ }^{18}$ Almost all CMOs appealed the decision, and in 2013 the General Court partially annulled the DG COMP's decision, yet only in respect of the question of whether the CMOs had engaged in concerted action - not in respect of membership and exclusivity clauses 19

\footnotetext{
${ }^{11}$ Gyertyánfy, 69 pointing towards the first GEMA decision of 2 June 1971.

${ }^{12}$ These were: the Santiago Agreement covering the rights of online public performance (by the author societies' umbrella organisation CISAC); and the Barcelona Agreement covering digital reproduction (issued by the mechanical collecting societies' umbrella organisation BIEM).

${ }^{13}$ European Commission, Notification of cooperation agreements (Case COMP/C-2/38.377 - BIEM Barcelona Agreements), (2002/C 132/10) and European Commission, Notice published pursuant to Article 27(4) of Council Regulation (EC) No 1/2003 in Cases COMP/ C2/39152 - BUMA and COMP/C2/39151 SABAM (Santiago Agreement COMP/C2/38126), (2005/C 200/05). See European Commission, Press Release IP/04/586 of May 3, 2004.

${ }^{14}$ Lüder (2007), 655.

${ }^{15}$ For a comprehensive overview on CJEU case law on representation agreements prior to 2008, see Gyertyánfy 67f.

${ }^{16}$ In 2000, RTL filed a complaint against the German CMO GEMA because it had requested a pan-European multi-repertoire license which had been rejected by GEMA on the grounds that it only held multi-repertoire for Germany. In 2003, Music Choice Europe filed a complaint against the umbrella organisation CISAC, claiming that the model standard contract was a concerted practice to avoid competition between CMOs.

${ }^{17}$ Cf. European Commission, CISAC decision, recital 14, 9.

${ }^{18}$ See Gyertyánfy (2010), 73.

${ }^{19}$ Case T-442/08 CISAC v European Commission.
} 
Beyond its assessments concerning competition law, the European Commission has also sought to scrutinise multi-territorial licensing from a Single Market perspective. In 2004, having observed the collective management of copyright for several years, a Communication was issued stating that "more common ground on several features of collective management is required" in order to achieve the Single Market ${ }^{20}$ The Commission opted for a soft-law instrument, and in May 2005 published its Recommendation 2005/737/EC on collective cross-border management of copyright and related rights for legitimate online music services. Aiming to introduce competition both up- and downstream 21 it advocated the introduction of multi-territorial licenses and stipulated that rightholders should have the right to assign the management of their online rights necessary to operate online music services to a CMO of their choice, irrespective of the residence or the nationality of either the CMO or the rightholder (Article 3) ${ }^{22}$

As Drexl (2007) notes, in utilising this model the Recommendation opted for a "totally new system of direct licensing without relying on reciprocal representation agreements' 23 instead of recommending a system similar to the IFPI/Simulcasting model for RRAs ${ }^{24}$ Academics and various stakeholders have criticized the Commission's approach and the consequences it had regarding the licensing practice 25

\subsection{Emergence of multi-territorial mono repertoire direct licensing}

At the beginning of 2006, the licensing landscape began to change fundamentally when a major music publisher withdrew its mechanical rights for the online use

\footnotetext{
${ }^{20} \mathrm{Cf}$. European Commission, Communication from the Commission to the Council, the European Parliament and the European Economic and Social Committee, The Management of Copyright and Related Rights in the Internal Market (16.04.2004), COM(2004) 261 final, 19.

${ }^{21}$ See Lüder, 656

${ }^{22}$ See also Sebastian Felix Schwemer, 'The licensing of online music streaming services in Europe' in Richard Watt (ed), Handbook of the Economics of Copyright, A guide for Students and Teachers (Edward Elgar 2014), 152.

${ }^{23}$ Josef Drexl, 'Competition in the field of collective management: preferring "creative competition" to allocative efficiency in European copyright law' in Paul Torremans (ed), Copyright Law, Handbook of Contemporary Research (Edward Elgar 2007) 280.

${ }^{24}$ The situation for simulcasting or webcasting (i.e. non-interactive broadcasting of musical works via the Internet) is somewhat special and outside the scope of this chapter. It is, however, noteworthy that the fear of competition by means of price dumping was not shared. RRAs regarding the licensing of the related rights of phonogram producers did not contain an economic residence clause thus enabling competition between CMOs; the European Commission thus granted an antitrust exemption (European Commission, Decision of 8 October 2002 relating to a proceeding under Article 81 of the EC Treaty and Article 53 of the EEA Agreement (Case No COMP/C2/38.14 - IFPI "Simulcasting"), 2003/300/EC).

${ }^{25}$ For instance, Drexl (2007) argues that the Recommendation focuses on output and price in terms of a static competition model "without taking into account the purpose of copyright to promote creativity and cultural diversity".
} 
of its Anglo-American repertoire from the respective national CMOs ${ }^{26}$ Instead, it enshrined its rights in customized licensing entities that use a direct license model for a single repertoire on a multi-territorial basis 27

The other major publishers and several independent publishers followed suit with similar models which appointed their rights to new licensing entities or CMOs as exclusive or non-exclusive agents. Interestingly, the newly formed entities were in several instances formed as subsidiaries of major European CMOs. This process may have been negotiated at the expense of smaller CMOs, as Guilbault and van Gompel (2010) point out 28 Most importantly, these developments meant a further fragmentation of repertoire 29 As a result, national CMOs could no longer grant licenses for the entire global repertoire. Instead, a licensee was required to obtain licenses both from the national CMO and via the mono-repertoire licensing arrangements 30

Yet the phenomenon of multi-territorial licensing remains inextricably intertwined with mono-territorial licensing (i.e. licensing for only one country) ${ }^{31}$ Musical works often have several authors and may be published by more than one publisher ${ }^{32}$ These split copyrights mean that it is sometimes not sufficient to clear rights with only one rightholder in order to cover a single song (see also recital 37 of Directive 2014/26/EU). Ultimately, from the online service providers' and consumers' perspective, the aggregation of a global repertoire is the major concern, as the European Parliament's Committee on Legal Affairs points out ${ }^{33}$ The fragmentation of rights, rightholders and repertoires is at the core of high transaction costs 34 - which collectivization of rights management

\footnotetext{
${ }^{26}$ CELAS (Central European Licensing and Administration Services) was a licensing agency jointly owned by the German and British CMOs GEMA and PRS for Music. CELAS provided a one-stop shop for the repertoire of EMI Music Publishing for online exploitation. In 2014, Sony/ATV Music Publishing, PRS for Music and GEMA launched a new joint venture called SOLAR - a one-stop shop for the Sony/ATV and EMI music publishing licensing catalogue (see press release at: http://www.celas.eu/CelasTabs/Content/solarlaunch.pdf September 2014). This followed the acquisition of EMI Music Publishing by Sony in 2012. SOLAR replaced the CELAS and PAECOL licensing systems. For a more detailed overview, see Schwemer, 153-155.

${ }^{27}$ Giuseppe Mazziotti, 'New Licensing Models for Online Music Services in the European Union: From Collective to Customized Management' (2011) Columbia Public Law Research Paper No. 11-269, uses the term "customized" collective rights management. Dehin (2010), 228 refers to it as the "new rights managers model".

${ }^{28}$ Cf. Guilbault and van Gompel (2010), 161.

${ }^{29}$ See e.g. Riis (2011), p. 482.

${ }^{30}$ In 2012 , the European Commission estimated that approximately 30 licenses are needed in order to clear author rights for a pan-European service.

${ }^{31}$ See also Schwemer (2014).

${ }^{32}$ Gyertyánfy (2010), 65.

${ }^{33}$ Guilbault (2014), 770, citing European Parliament, Committee on Legal Affairs, Working Document on the proposal for a directive of the European Parliament and of the Council on collective management of copyright and related rights and multi-territorial licensing of rights in musical works for online uses in the internal market (COM(2012)0372 - C7-9183/2012 2012/0180(COD)) 4 March 2013.

${ }^{34}$ KEA Affairs (2012), Licensing music works and transaction costs in Europe, 51.
} 
originally aimed to reduce.

The development of these novel direct licensing arrangements must be seen in the context of the two actions taken by the EU Commission which sought to foster multi-territorial licensing of music rights for the Internet: the CISAC proceedings and Recommendation 2005/737/EC. The European legislator reflects in recital 39 of Directive 2014/26/EU that the Recommendation has not been sufficient to encourage the widespread multi-territorial licensing or to address the specific demands 35

Guibault (2014) concludes that the

"majority of scholarly commentators, policy makers and stakeholders agree that the intention behind the Recommendation of fostering competition between individual collective management organisations has created chaos rather than anything else. $\sqrt[36]{36}$

It is interesting to note that the European legislator has chosen not to apply the rules of the CRM Directive to mono-repertoire licensing entities. Since such entities represent only a single rightholder, they fall outside the scope of the definitions of Article 3 lit (m) Directive 2014/26/EU.

\subsection{Licensing hubs formed by author CMOs}

More recently, new influences have appeared in the online music licensing ecosystem: several collective management organisations have joined forces and formed so-called 'licensing hubs' with the aim of providing a one-stop solution for acquiring licenses for online use of music.

These licensing hubs differ from the mono-repertoire multi-territorial direct licensing entities (see section above) in terms of the repertoire they license: a licensee can acquire a multi-territorial license for the joint repertoire of all the CMOs taking part in the respective hub model (multi-territorial, multirepertoire).

The emergence of these hubs began as early as 2007, when the Spanish, French and Italian author-CMOs (SGAE, SACEM and SIAE respectively) announced their joint one-stop shop licensing platform Armonia. While officially formed as European Economic Interest Grouping (EEIG) in 2013, this hub actually licensed its first deal in November 2012 37 Several other CMOs joined

\footnotetext{
${ }^{35}$ While a Recommendation is a soft-law tool, it is taken into account by the CJEU when interpreting the acquis communitaire.

${ }^{36}$ Guilbault (2014), 763. Gyertyanfy (2010), 85, for example, states that the "Commission successfully demolished an essential element of collective management - in exchange for very few competition law advantages".

${ }^{37}$ For more see: Schwemer (2014), 159.
} 
the hub, which currently covers repertoires of SACEM (France and Luxembourg), SGAE (Spain), SIAE (Italy), SPA (Portugal), SABAM (Belgium), Artisjus (Hungary), SUISA (Switzerland) and a bulk of Anglo-American and LatinAmerican works 38 The German, Swedish and British societies GEMA, STIM and PRS for Music have announced a similar initiative, which has recently been approved by the European Commission in an investigation under the EU Merger Regulation 39 Since 2009, the Nordic and Baltic states have had a cooperation model in place which allows users to obtain a license covering mechanical reproduction and performance rights for online exploitations from a single source for the respective territories. In this setup, Nordisk Copyright Bureau (NCB), which is owned by the Nordic author-CMOs, acts as a single entry point for the licensee but does not hold the respective rights.

This trend towards licensing hubs of CMOs can partially be seen in the context of the licensing regime that Directive 2014/26/EU proposes with the aim of facilitating the re-aggregation of rights for online use. In the preparatory work for the Directive, the European legislator opted for a model referred to as 'European Licensing Passport'. While the notion of a passport-model was dropped in the final Directive, the legislator kept the basic idea, now enshrined in Articles 24 and 30 of Directive 2014/26/EU. Entities, which must fulfil certain minimum requirements, are expected to aggregate repertoire for multi-territory licensing. Local uses, on the other hand, would still be licensed by the national collective management organisation. As I have pointed out earlier, the European Commission expects that by encouraging the voluntary aggregation of music repertoire, the number of licenses a user needs to obtain in order operate a multi-territorial service shall be reduced 40

Thus, the legislator has further narrowed the autonomy space in which CMOs operate. The CRM Directive must be implemented by the Member States by 10 April 2016. The re-aggregation is mainly based on voluntary actions by CMOs and it is still too early to predict whether the licensing hub-model will be more broadly used and lead to the predicted market consolidation.

\subsection{Towards new players and (even more) direct licensing?}

As noted, the market for online licensing is under transition. There have been several recent controversies, where rightholders either have chosen not to license their content catalogue for online exploitation by music streaming services or

\footnotetext{
${ }^{38}$ See Armonia press release, available at: http://www.armoniaonline.eu/release/ SUISAjoinsEN.pdf

${ }^{39}$ See European Commission, Press release IP/15/5204 (16 June 2015) in Case M.6800 PRSfM/STIM/GEMA/JV.

${ }^{40}$ See European Commission, Impact Assessment 2012, 163. Recital 24 of the proposed Directive. Schwemer, 157.
} 
pulled their catalogue. Besides the question of whether streaming constitutes a substitute for other forms of consumptions 41 royalty rates have been a key concern. Rightholders have expressed their discontent with the negotiations led by the CMOs to which they have transferred their rights for exploitation. In a context characterised by increased transparency and technical means (namely backend software and reporting standards) academics, rightholders and users pose the question as to whether the traditional setup of collective management organisations is the most efficient means of licensing content ${ }^{42}$

In the US, a new player called Global Music Rights (GMR) ${ }^{43}$ is aiming to take on music publishing incumbents for performance rights. Through direct licensing of selected popular songwriters, the licensor aims to negotiate higher royalties than the counterparts BMI and ASCAP. This leverage exists, for example, because GMR can refuse permissions regarding its songs, while the incumbents are highly regulated and need to offer blanket licenses ${ }^{44}$ While this specific example has to be seen in the context of the US ecosystem, it seems reasonable to consider whether similar developments would be possible in Europe.

The CRM Directive opens up for direct licensing in respect to multi-territorial licensing under certain conditions in order to prevent a national repertoire lockin. Article 31 of Directive 2014/26/EU regulates that rightholders can withdraw their online rights in musical works from traditional CMOs so as to grant multiterritorial licenses for their online rights in musical works themselves or through any other party they authorise or through any collective management organisation complying with the provisions of the Directive. Rightholders do not have to withdraw those rights from their CMO for the purpose of mono-territorial licensing. Guibault (2014) notes the critique expressed by the CMO umbrella organisation GESAC which argues that the direct licensing possibility in Article 31 contradicts the principle of exclusivity in the assignments of rights in favour of the initial $\mathrm{CMO} 45$

In Article 3 lit (b) the legislator also introduced the new notion of 'independent management entities' 46 The main difference between collective manage-

\footnotetext{
${ }^{41}$ For an economic analysis see: Godefroy Dang Nguyen, Sylvain Dejean \& François Moreau, 'Are streaming and other music consumption modes substitutes or complements?' (2012) available at: http://ssrn. com/abstract=2025071

${ }^{42}$ For a discussion of the traditional rationales for collective management in the digital era, see Katz (2006).

${ }^{43}$ More information at: http://globalmusicrights.com

${ }^{44}$ See: $\quad$ http://wWw.nytimes.com/2014/10/30/business/media/ new-venture-seeks-higher-royalties-for-songwriters.html

${ }^{45}$ Guilbault (2014), 775 with more references.

${ }^{46}$ Art. 3 lit (b) it defines 'independent management entity' as any organisation "which is authorised by law or by way of assignment, license or any other contractual arrangement to manage copyright or rights related to copyright on behalf of more than one rightholder, for the collective benefit of those rightholders, as its sole or main purpose, and which is: (i)
} 
ment organisations and an independent management entity lies in the ownership or control structure; the latter is neither owned nor controlled by rightholders and is organised on a for-profit basis. So far, there is some ambiguity as to what such entities are and it remains a matter of speculation as to whether the European legislator had such developments in mind 47

It remains to be seen how Member States will choose to implement the definition and the rule in Article 31, which is directed towards situations where a CMO does not grant or offer to grant multi-territorial licenses or does not allow another CMO to represent those rights for such purpose by 10 April 2017.

\subsection{The operational picture}

In the context of cross-border licensing, the user generated law framework may need to consider the relevance not only of initial licensing and renegotiation but also the operations of such services. Many challenges in relation to online music are not directly related to licensing but reside in the operational processes such as documentation and reporting from service providers about played tracks and the payment of royalties from the respective organisations to their rightholders 48 There have been several initiatives to tackle some of these operational challenges. The Global Repertoire Database, for example, was an industry initiative started in 2008 with the goal of creating a joint database covering ownership and control of musical works. The Swedish CMO has started a supplier for business process outsourcing services, International Copyright Enterprise (ICE). In 2012, Network of Music Partners (NMP) was founded and it centres its activities on the administrative processes of invoicing for use of music and distributing royalties. NMP is jointly owned by NCB and PRS for Music. NMP handles the administrative back-office inter alia for the NordicBaltic online markets and the pan-European central licensing of the EMI catalogues. Front-office activities such as licensing and member services remain with the parent companies (NCB and PRS for Music). The services by NMP and ICE are also used by other European CMOs, for example the Dutch society

neither owned nor controlled, directly or indirectly, wholly or in part by rightholders; and (ii) organised on a for-profit basis". In recital 15 to Directive 2014/26/EU, those are described as commercial entities inter alia because they are not owned or controlled by rightholders. However, to the extent such independent management entities carry out the same activities as collective management organisations, they should be obliged to provide certain information to the rightholders they represent, collective management organisations, users and the public.

${ }^{47}$ Given the reference to 'collective benefit' in the definition of an independent management entity, the feature that rightholders have no control makes the provision somewhat contradictory. Recital 16 contains a list of what should not be regarded 'independent management entities'.

${ }^{48}$ The European Commission, for example, mentions the outsourcing of back-office functions in the accompanying memo to its proposal for the CRM Directive (MEMO/12/545 at point 15). See also my prior research in Schwemer (2014). 
Buma/Stemra ${ }^{49}$ In addition, several standards such as DDEX, CCID or ISNI have been developed for tasks like reporting and invoicing.

\section{The online music-licensing ecosystem as an example of user gen- erated law}

The previous section illustrates that multiple intertwined developments and arrangements for the licensing of music online have occurred and that they must be seen in their distinct historical context. This section analyses how well these developments accord with the user generated law framework. Does the example of online licensing pass all phases of the theoretical model? Why have the licensing arrangements been created in the first place? Do all determinants from the methodological model have an influence on the emergence of the specific user generated law?

There are multiple entry points to the process of evaluating the legal innovations created by users. Firstly, model contracts (as in the case of the Barcelona and Santiago Agreements or CISAC terms) could be seen as examples where users create a layer of private regulation. A second starting point is the emergence of multi-territorial mono-repertoire licensing entities which has happened since 2006. Thirdly, the more recent development of licensing hubs formed by CMOs seems worthy of further scrutiny. In addition, other current developments such as a potential move towards more direct licensing or legal arrangements outside of licensing (e.g. regarding operations) could be relevantly construed under the framework. The focus of this chapter will be on the first three examples.

\subsection{Autonomy spaces and interdependencies between the licensing models}

The developments around cross-border licensing models are characterised by an interplay between private arrangements and regulatory activity. This interaction is between self-organisation on one side, and soft-law measures (such as green papers), and Recommendations, and recent legislative measures, as well as competition proceedings on the other side. Such interactions are an important consideration when applying the user generated law framework to these licensing models. This dynamic can partly be understood according to what is termed autonomy spaces in user generated law methodology. Autonomy spaces refer to State-enacted law that defines a space within which persons or organisations

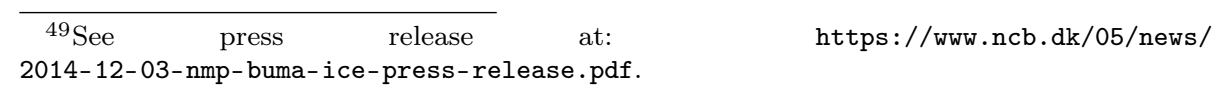


may act autonomously 50

Collective management organisations are regulated to a varying degree across European countries and set up in a range of ways. In some cases, for example, national organisations are de facto monopolies and in other cases de jure monopolies 51 The degree of regulation can also vary: the German CMOs, for instance, were traditionally highly regulated, while the French CMOs were intermediately regulated, and the British CMOs lightly regulated 52 Thus, European CMOs traditionally had different spaces to operate in.

In addition, there might also be a certain interplay between the different licensing models. Have the Barcelona and Santiago standard agreements served as inspiration for later models or prepared conditions for them? Is the licensing hub idea implemented in the current multi-territorial licensing models? Or are all arrangements more or less independent developments, created without reference to other or earlier models? Given the complexity of the developments in a field that is not static but constantly developing, it is difficult to obtain a clear picture; but it is safe to say there have been at least some interdependencies. While further exploring these questions does not fall within the scope of this chapter, it is important to acknowledge that the correlations between the different licensing models can point towards the dissemination criterion of the user generated law model. If a licensing model has been copied or served as inspiration for later constructions, the original model has been disseminated and thus further processed within the model framework.

Figure 1, below, displays a simplified overview of the evolution of the licensing arrangements which have been described in the first part of this chapter. The traditional landscape consisted of national CMOs, which - via reciprocal representation agreements (RRAs) based on model contracts - were able to grant mono-territorial multi-repertoire licenses. In light of the CISAC decision and the Recommendation of 2005, new customised licensing entities which license multi-territorial on a mono-repertoire basis have emerged as additional licensors. Directive 2014/26/EU codifies some of the developments and promotes inter alia a regime of licensing HUBs in which CMOs join forces to license on a multi-territorial and multi-repertoire basis, potentially leading to the reaggregation of rights. Besides this, the Directive differentiates between CMOs and so-called independent management entities (IMEs) which are organised on a for-profit basis and are neither owned nor controlled, directly or indirectly,

\footnotetext{
${ }^{50}$ Riis, Chapter 1 of this book.

${ }^{51}$ In Italy or Austria, for example, CMOs are regulated as legal monopolies. See e.g. G. M. Riccio, G. Codiglione, Copyright Collecting Societies, Monopolistic Positions and Competition in the EU Single Market (2014) 7 Masaryk U.J.L.Tech., 287.

${ }^{52}$ An overview of how CMOs in several countries have been regulated is given by Besen Kirby, Compensating Creators of Intellectual Property, Collectives That Collect (1989).
} 
wholly or in part, by rightholders. It is important to note that the different licensing arrangements have not necessarily replaced each other but rather added additional licensing layers over time.

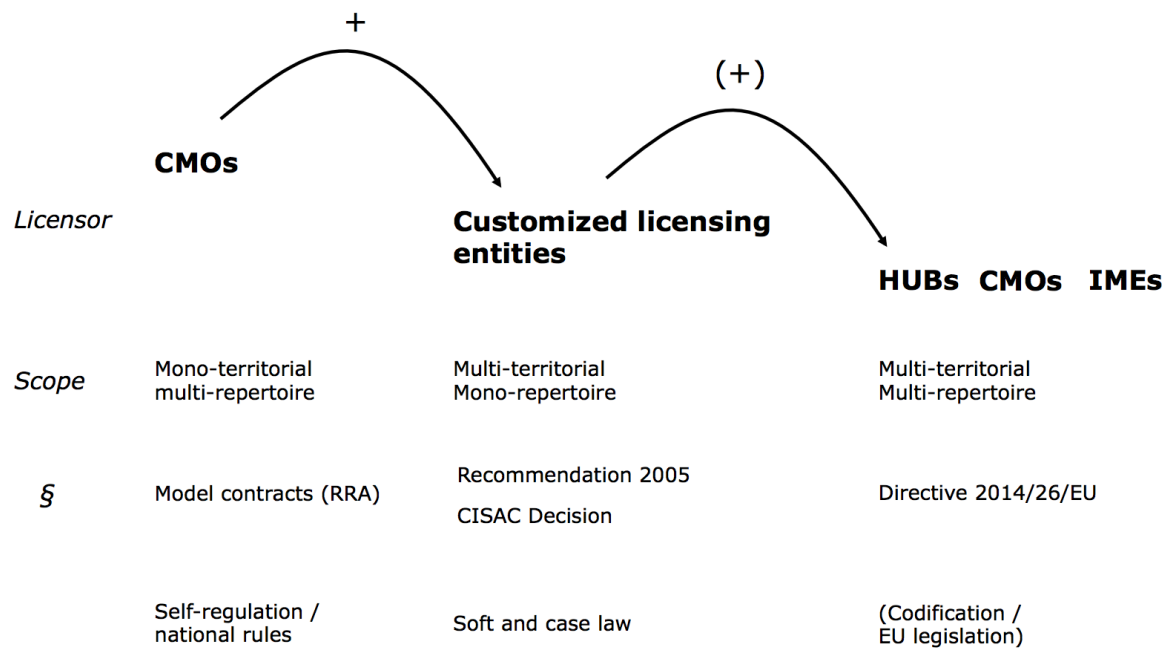

Figure 1: Evolution of licensing arrangements

\subsection{The emergence of cross-border models}

The first phase of user generated law is the emergence phase which is deemed to rely on four determinants: (1) heterogeneous demands for legal solutions, (2) expectation of benefits, (3) asymmetric information and (4) the existence of one or more lead users. Can those four determinants construe the emergence of private regulatory models within this sub-space of intellectual property rights?

\subsubsection{Heterogeneous demand}

The first determinant for the emergence of user generated law is held to be the heterogeneous demand for legal solutions. Though not contained in the original model by Eric von Hippel, the cross-border dimension is proffered as a crucial element within the user generated law framework 53 The Internet's borderless technological nature enables users to access content from all over the world. Online licensing is inherently more of a cross-border undertaking than traditional offline licensing. This is also where the heterogeneity lies. Existing licensing

\footnotetext{
${ }^{53}$ Riis, Chapter 1 of this book.
} 
models, it appears, have not been able to deal with cross-border licensing in the digital context.

As I have noted in the findings of earlier research:

"music-streaming services usually approach their markets on a territorial and not on a pan-European level. The decision to enter a local market is influenced by a combination of several elements: one key consideration constitutes the ability to get the respective rights at a cost efficient level. A second key consideration concerns the general economic situation and the general legal context of the respective local market.' 5

\subsubsection{Expectation of benefits}

Private regulatory models are supposedly only created if users can expect benefits from them (i.e. the models generate value by being used). This condition is fulfilled if the parties (rightholders and licensees) benefit from the licensing models. We can differentiate between regulatory models that do not require an institutional set-up (e.g. pure contractual agreements) and models that do (e.g. copyright collective management organisations that require an organisation to collect remuneration) 55 The greater the set-up costs involved, the greater the expected benefits must be in order for a private regulatory model to be deployed. KEA Affairs (2012) identifies in its report on online music licensing that the fragmentation of rights, rightholders and repertoires is at the core of high transaction costs in Europe 56 On this issue, the European legislator formulates the aspiration of the CRM Directive to facilitate new online services and thereby enhance consumer choice and lead to a reduction in transaction costs which should be passed on to consumers 57 When imposing legislation on the space, the Commission expresses its expectation that music publishers would consider "re-entrusting part of their rights to collecting societies that comply with passport requirements and fulfil certain conditions of good governance" 58 The mere existence of the multi-territorial licensing arrangements suggests that either the parties enjoy benefits or that the legislator has forced these models 59

\footnotetext{
${ }^{54}$ Schwemer (2014), 150

${ }^{55}$ Riis, Chapter 1 of this book.

${ }^{56}$ KEA Affairs (2012), 51.

${ }^{57}$ Recital 44 of Directive 2014/26/EU.

${ }^{58}$ See European Commission, Impact Assessment 2005, 162. CELAS, for example, concluded sub-agency agreements with collecting societies such as KODA (DK), STIM (SE) and TEOSTO (FI).

${ }^{59}$ It is an open question as to whether the users benefit as well, considering the monopoly power of rightholders.
} 


\subsubsection{Asymmetric information}

Compared to legislating multi-territorial licensing, private arrangements are argued to be better at addressing the problematic asymmetry of information possessed by the legislator and the parties affected by the law. The ensuing argumentation and narrative adheres closely to the discussion in the previous chapter on "Collective Agreements for the Clearance of Copyrights - The Case of Collective Management and Extended Collective Licenses" with minor adjustments. In practice, the legislator will regularly lack the requisite information for solving the task in an optimal way. A freely organized multi-territorial licensing regime between the different parties will be based on much more adequate information than a decision made by the legislator. In this way, asymmetric information is an essential dynamic in the emergence of cross-border licensing models. In regard to such cross-border licensing, the legislator has partly regulated the field with the CRM Directive. This has implications for the adoption of the legal innovations and will be discussed in the section devoted to that part of the model.

\subsubsection{The existence of one or more lead users}

The existence of individual or multiple lead users is the final element that is said to foster the formation of user generated law. Initially, it is important to identify the 'users' in the $\mathrm{CMO} /$ new licensing entities model. Users in user generated law are not only the persons subjected to but also affected by the law. A reasonable starting point when identifying 'users' is to look towards the relationship between licensors and licensees. In downstream licensing this would be the relation of collective management organisations to online music service providers. Here, service providers acquire a license for the respective repertoire from a CMO. A second horizontal licensing relation can be found between the CMOs where organisations via reciprocal representation agreements enable each other to offer licenses for other CMOs' repertoires in their respective territory.

When looking at the horizontal relation between collective management organisations, industry umbrella organisations have played a crucial role in developing model contracts and facilitating best practices. As noted in the previous section, the organisations CISAC and BIEM have developed several model contracts for their member organisations. While information on the exact development of these model contracts is scarce, one can assume that the umbrella organisations have acted in a fashion that matches the definition of a lead user. However, one caveat in regard to the model is related to motivation: Schovsbo (2010) emphasises the importance of acknowledging that CMOs like all other institutions "have a vested interest in maintaining a system which is dependent 
on their services.

In the downstream relation it is more difficult to draw a clear picture. One can assume that online music service providers (and possibly rightholders themselves) have pushed CMOs to offer the requested licenses ${ }^{61}$ Yet there is no clear evidence available that this would have led to the development of private regulation. Scrutiny of the commercial motivations of those involved suggests that service providers initially had little interest in multi-territorial licensing models since they approached markets for commercial reasons on a country-by-country basis.

In relation to the emergence of direct licensing (i.e. multi-territorial monorepertoire licensors like CELAS) the Court argues in the CISAC case that:

"the abandonment of the exclusivity clause made possible certain developments in the market, namely the grant of the first direct licenses, which are necessary if an eventual move beyond the national territorial limitations is to be envisaged $\sqrt{62}$

The court continues that:

"[t]he spread of direct licensing required, in particular, that a demand for such licences develop on the part of major users which - instead of turning to the collecting societies of all the countries in which they operate - would prefer to acquire direct licences, valid worldwide, over the repertoires which interest them.: 63

The foundation of CELAS was announced in early 2006, making it the first mover in the field. Anecdotal evidence shows that the major (US American) repertoire rightholders behind the novel licensing entities and arrangement had a preference for this setup 64 On the other hand, smaller rightholders such as those dealing with niche repertoire might not necessarily gain the same benefits from this setup 65 The large incumbents acted in a fashion described as lead users within the user generated framework.

When looking at licensing HUBs, the initiating CMOs such as the founding societies of Armonia have taken a lead user role. In a different field (visual arts) a comparable one-stop shop by the respective CMOs has been offered by OnLineArt S.C.R.L since 2002. While the European legislator makes reference to this model in some of its documents, it is unclear to what extent the solution

\footnotetext{
${ }^{60}$ See Schovsbo, Jens, The Necessity to Collectivize Copyright - And Dangers Thereof (June 30, 2010). (Available at SSRN: http://ssrn.com/abstract=1632753) 9.

${ }^{61} \mathrm{Cf}$. also footnote 66.

${ }^{62}$ Recital 125, CISAC Case T-442/08.

${ }^{63}$ Recital 127, CISAC Case T-442/08

${ }^{64}$ See e.g. Gyeryánfy (2010), 59

${ }^{65}$ Compare Lüder (2007), 657.
} 
for online music licensing has been inspired by this setup. The Nordic-Baltic onestop storefront solution offered by $\mathrm{NCB}$ also exhibits similarities. In this context, the CRM Directive appears as codification parallel to the developments of the market (also discussed below under 'adoption phase'). The Directive has to be implemented by the Member States by April 2016, so in a way the CMOs are early in adopting this model; but one could argue that the latest developments are at least partially imposed by the regulative context. This is also supported by the fact that in its Recommendation of 2005 the European Commission was envisioning the pooling of repertoire into a major online licensing platform 66

In summary, it is evident that this process has relied on the engagement of different lead users with different levels of involvement. CMOs feature as users, along with the community consisting of rightholders and other relevant stakeholders in the industry. Yet rightholders themselves have also engaged in the process in ways which resemble the lead user paradigm.

\subsubsection{Diffusion phase}

Once new licensing arrangements emerge, communities form around the legal innovation. This is the second phase of the user generated law framework. The framework does not offer further refinement of the community definition which can be understood in both a broad and a narrow sense.

Model contracts developed by umbrella organisations have been used by CMOs as a basis for their bilateral reciprocal agreements 67 In regard to multiterritorial mono-repertoire licensing, entities like CELAS, all other major publishers, and several independent publishers have followed suit and adopted similar models. In the case of licensing HUBs, several other collective management organisations have joined Armonia. Thus, it appears that all of the described licensing arrangements have formed more or less broad communities around them.

\subsubsection{Adoption phase}

In terms of the adoption of legal innovations, the user generated law methodology foresees two forms for this which both take their starting point in the legislator: private regulatory models evolve either as new layers of law based on State-enacted law or as sui generis legal systems. Again, it is useful to differentiate between the arrangements as legal innovations: model contracts, multi-territorial mono-repertoire licensing entities, and licensing hubs.

\footnotetext{
${ }^{66}$ On the matter of authors, composers and publishers pooling into one platform, see Lüder (2007), 656.

${ }^{67}$ See e.g. Lüder (2007), 654.
} 
As seen in section 3.1, there is a distinct interplay between private initiatives and regulatory activity in the sphere of online music licensing. A lack of satisfactory legal innovation (in this context referring to a solution for cross border licensing of online music) led the legislator to come up with a non-binding instrument, namely the Recommendation of 2005, in order to achieve its policy goals. Almost one decade later, the legislator has regulated part of the playing field. The CRM Directive aims towards the establishment of hubs for the licensing of online music by author-CMOs. In this context it is interesting to note that the European legislator has chosen not to apply the rules of the CRM Directive to the mono-repertoire licensing entities 68 In the working documents accompanying the Directive there is no evidence that would offer further insight into the legislator's reasoning. This might point towards the fact that the European Commission has been satisfied with the developments in the space. As seen above, the development of initiatives such as Armonia dates back to before the entry into force of the Directive but after the Recommendation. Regarding the codification of this specific licensing form, it appears that the legislator does not adopt the legal innovations but rather takes action in order to define the playing field for licensing - the autonomy space - given the lack of satisfactory solutions provided by the actors.

Competition authorities have also been actively involved in stirring up the licensing arrangements. This ultimately meant that the lead users (umbrella organisations) and its community (CMOs) did not pursue their legal innovation further (reciprocal representation agreements based on model contracts containing customer allocation clauses) culminating in the CISAC proceedings. The intervention of DG COMP does not imply a failing of the user generated law, but suggests rather that the model has been partly adopted and the respective autonomy space corrected. Other initiatives to facilitate industry solutions represent a further grey-zone regarding the legislator's engagement 69 All told, it seems that the case of multi-territorial licenses is not easily put into the existing categories and that more levels of adoption might arise from this complexity.

\section{Concluding remarks}

For over a decade, stakeholders have been busy adapting the traditional licensing arrangements for online music licensing from the territorial tradition of copyright to the cross-border and multi-territorial reality of a knowledge society. In the user generated law framework, "law that accommodates the needs of the knowledge society" is characterised by (1) flexible norms, (2) with cross-

\footnotetext{
${ }^{68}$ See discussion above under section 2.2.

${ }^{69}$ For example the Licenses for Europe stakeholder dialogue (2014).
} 
border scope and (3) which are industry- and subject-specific. It appears that the developments in cross-border licensing of music rights are in many ways a prototype of those characteristics. The licensing solutions are highly industryand subject-specific: namely addressing the situational need for interactive ondemand streaming, thus permitting users to actively choose the musical works and the time of consumption, and thereby reflecting the heterogeneity in demand for legal solutions. The cross-border element has also been crucial in the development of legal solutions, reflecting the global dimension of the content and its distribution via the Internet. Finally, the question arises as to whether the norms are flexible, reflecting the complexity and the fast pace of development. One could argue that because of the highly specific subject matter related to a technological and market phenomenon (i.e. streaming of music), these new developments are not sufficiently covered to qualify as flexible. Understanding flexibility within this subspace, it appears that the norms are sufficiently adaptive. In the case of music licensing, it is striking that in different facets the European legislator has played an important role: an interplay that is challenging to construe within the user generated law framework.

The developments in the licensing landscape must be seen in the multifaceted context of enabling the Digital Single Market across all European Member States; fostering innovation of new digital service providers in Europe; addressing competition concerns towards the collective management of rights; and dealing with the legacy of the traditional territorial nature of copyright administration and exploitation. The regulatory framework and new ways of exploitation affect the formation of private mechanisms of clearance of copyrights. Only time will reveal whether the current licensing arrangements are fit for purpose and able to facilitate future (and even already existing) services like Soundcloud, where mashups and remixes are a major part of the content.

Music is often described as a harbinger for other forms of entertainment goods, and the trend towards on-demand access can be seen in the number of consumers now watching films and TV productions via services like Netflix, or accessing books via commercial players like Oyster in the US or Mofibo in Denmark or the Bokhylla (Norwegian for "bookshelf") project by the Norwegian national library. These industry verticals face similar market challenges, but may have gone through different developments (or indeed some common trends) concerning their licensing models. By also applying the user generated law model to those verticals, the paradigm will be tested further which may in turn provide important policy implications. 